\title{
Inhibitory Potencies of Several Iridoids on Cyclooxygenase-1, Cyclooxygnase-2 Enzymes Activities, Tumor Necrosis factor- $\alpha$ and Nitric Oxide Production In Vitro
}

\author{
Kyoung Sik Park, Bong Hyun Kim and II-Moo Chang \\ Natural Products Research Institute, College of Pharmacy, Seoul National University, 28-Yungun-dong, \\ Jongro-ku, Seoul 110-460, Korea
}

\begin{abstract}
To verify the anti-inflammatory potency of iridoids, seven iridoid glucosides (aucubin, catalpol, gentiopicroside, swertiamarin, geniposide, geniposidic acid and loganin) and an iridoid aglycone (genipin) were investigated with in vitro testing model systems based on inhibition of cyclooxygenase (COX)-1/-2 enzymes, the tumor necrosis factor- $\alpha$ (TNF- $\alpha$ ) formation and nitric oxide (NO) production. The hydrolyzed-iridoid products (H-iridoid) with $\beta$-gludosidase treatment only showed inhibitory activities, and revealed different potencies, depending on their chemical structures. Without the $\beta$-gludosidase treatment, no single iridoid glycoside exhibited any activities. The aglycone form (genipin) also did not show inhibitory activities. To compare anti-inflammatory potency, the inhibitory concentrations $\left(\mathrm{IC}_{50}\right)$ in each testing system were measured. The hydrolyzed-aucubin product (H-aucubin) with $\beta$-gludosidase treatment showed a moderate inhibition on COX-2 with $\mathrm{IC}_{50}$ of $8.83 \mu \mathrm{M}$, but much less inhibition $\left(\mathrm{IC}_{50}, 68.9 \mu \mathrm{M}\right)$ on COX-1 was noted. Of the other $\mathrm{H}$-iridoid products, the H-loganin and the H-geniposide exhibited higher inhibitory effects on COX-1, revealing $\mathrm{IC}_{50}$ values of 3.55 and $5.37 \mu \mathrm{M}$, respectively. In the case of TNF- $\alpha$ assay, four $\mathrm{H}$-iridoid products: $\mathrm{H}$-aucubin, H-catalpol, $\mathrm{H}$-geniposide and $\mathrm{H}$-loganin suppressed the $\mathrm{TNF}-\alpha$ formation with $\mathrm{IC}_{50}$ values of $11.2,33.3$, 58.2 and $154.6 \mu \mathrm{M}$, respectively. But other $\mathrm{H}$-iridoid products manifested no significant activity. Additional experiments on NO production were conducted. We observed that only the $\mathrm{H}$-aucubin exhibited a significant suppression with $\mathrm{IC}_{50}$ value of $14.1 \mu \mathrm{M}$. Genipin, an agycone form, showed no inhibitory effects on all testing models, implying the hydrolysis of the glycosidic bond of iridoid glycoside is a pre-requisite step to produce various biological activities.
\end{abstract}

Keywords: anti-inflammation - cyclooxygenase - iridoids - nitric oxide - tumor necrosis factor- $\alpha$

\section{Introduction}

Iridoids represent a group of natural constituents with a monoterpene cyclic ring. They exist usually as glycosidic forms in nature, but are also found on rare occasions as an aglycone. Iridoids manifest dual facets of biological activities; one is to act as a defensive substance for

For reprints and all correspondence: Il-Moo Chang, Natural Products Research Institute, College of Pharmacy, Seoul National University, 28-Yungun-dong, Jongro-ku, Seoul 110-460, Korea. Tel: + 82-2-7408921; Fax: +82-2-745-1015; E-mail: changim@snu.ac.kr certain plant species $(1,2)$, and the other is to produce a variety of pharmacological actions for animals. Many medicinal plants containing iridoids such as Plantago, Cornus, Rehmanniae, Scrophularia, Gentiana and Harpagophytum have long been used to treat various ailments in the East and the West. The pharmacological activities are summarized: treatment of hepatic dysfunction (3), stimulation of bile acid excretion (4), antimicrobial activities (5), antitumor activities (6), antidotal activities for noxious Amanita mushroom poisoning (7), antiviral activities against Hepatitis B virus (8) and 
anti-inflammatory activities (9). A variety of iridoids including Scropolioside A, scrovalentinoside, verminoside and ipolamiide have been reported to possess significant anti-inflammatory activities in vitro and/or in vivo assay systems.

The present study is aimed to verify the antiinflammatory potency of seven iridoid glucosides, and an aglycone form. Additional test samples derived from iridoid glycosides were also prepared by treating those seven iridoid glycosides with $\beta$-gludosidase: they are called the hydrolyzed-iridoid products (H-iridoid). Since our previous study (10) indicated that an iridoid glycoside, namely, aucubin exhibited various biological activities in vitro as it was treated with $\beta$-gludosidase to produce its hydrolyzed product (H-aucubin). As with the assay systems of anti-inflammatory activities, measurements of cyclooxygenases (COX-1 and COX-2) enzymes activities, tumor necrosis factor- $\alpha(\mathrm{TNF}-\alpha)$ formation and nitric oxide (NO) production were conducted in vitro. In addition, the inhibition concentration $\left(\mathrm{IC}_{50}\right)$ of each test sample was calculated to compare its potency.

\section{Methods}

\section{Materials}

Seven iridoid glucosides, namely, aucubin (99.5\%), catalpol (>98\%), loganin (>98\%), gentiopicroside $(>98 \%)$, swertiamarin $(>98 \%)$, geniposide $(99 \%)$, geniposidic acid $(>98 \%)$ and one genin, genipin $(>98 \%)$, were purchased from Wako Pure Chemical Industries, Ltd. (Osaka, Japan) (Fig. 1). Aspirin, piroxicam, meloxicam, rolipram, N-nitro-L-arginine methyl ester (L-NAME), 3-(4,5-dimethylthiazol-2-yl)-2,5-diphenyltetrazolium bromide (MTT), a lipopolysaccharide (LPS) (from Escherichia coli, 011: B4), arachidonic acid (AA), Griess reagent and $\beta$-glucosidase (EC 3.2.1.21) were obtained from Sigma Chemical Co. (St Louis, MO, USA). DMEM (Dulbecco's Modified Eagle's Medium) and RPMI1640 (Roswell Park Memorial Institute) medium and other reagents for cell cultures were obtained from Gibco BRL Life Biotechnologies (Gaithersburg, MD, USA). Enzyme-linked immunosorbent assays (ELISA) kits for the determination of $\mathrm{PGE}_{2}$ (prostaglandin $\mathrm{E}_{2}$ ) and $\mathrm{TXB}_{2}$ (thromboxane $\mathrm{B}_{2}$ ) were obtained from Cayman Chemical Co. (Ann Arbor, MI, USA). An interferon (INF)- $\gamma$, antimouse TNF- $\alpha$ monoclonal antibodies and a biotinylated secondary antibody were purchased from Pharmingen International (San Diego, CA, USA).

\section{MTT Cell Viability Assay}

The degree of mitochondrial respiration as an indicator of cell viability was assayed by measuring the

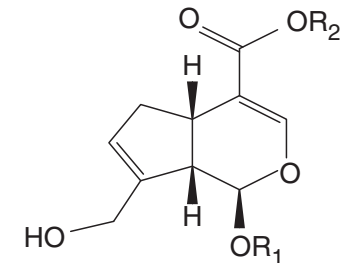

Genipin : $\mathrm{R}_{1}=\mathrm{H}, \mathrm{R}_{2}=\mathrm{CH}_{3}$ Geniposide : $\mathrm{R}_{1}=$ Glucose, $\mathrm{R}_{2}=\mathrm{CH}_{3}$ Geniposidic acid : $\mathrm{R}_{1}=$ Glucose, $\mathrm{R}_{2}=\mathrm{H}$
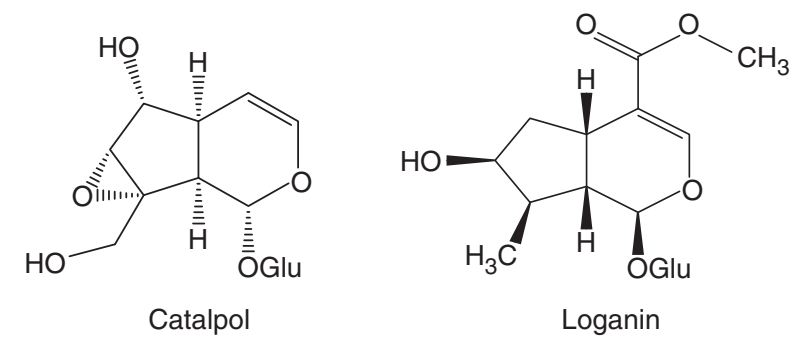

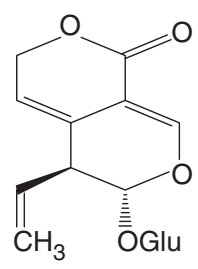

Gentiopicroside

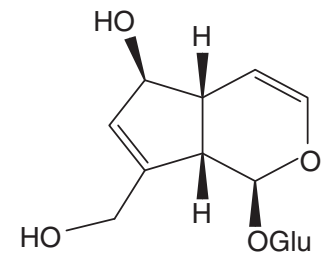

Aucubin
Figure 1. Chemical structures of iridoids tested.

mitochondria-dependant reduction of MTT to produce formozan crystals. Absorbance levels due to color changes were measured at 450 and $650 \mathrm{~nm}$ using the Automatic ELISA microplate reader (EL808, Bio-Tek Instrument Inc). Details of this experiment were reported previously (10).

\section{Cyclooxygenase-1(COX-1) Assay using Human Erythroleukemia (HEL) Cells}

The COX-1 assay with HEL cells (American Type Culture Collection, ATCC) was carried out using the method of Berg et al. (11). Briefly describing the culture condition: HEL 92.1.7 cells were grown in RPMI 1640 supplemented with a $10 \%$ heat-inactivated fetal bovine serum (HyClone) under $5 \% \mathrm{CO}_{2}$. Penicillin $(100 \mathrm{U} / \mathrm{ml})$ and streptomycin $(100 \mu \mathrm{g} / \mathrm{ml})$ were added to the culture medium. Then cells were harvested and re-suspended in a fresh medium at $1 \times 10^{7}$ cells $/ \mathrm{ml}$. The stock solutions of test compounds dissolved in DMSO were diluted with the medium just before the tests. A portion of cell suspension $(500 \mu \mathrm{l})$ was added to the testing sample solution $(250 \mu \mathrm{l}$ each), mixed and incubated for $30 \mathrm{~min}$ at $37^{\circ} \mathrm{C}$. Then, AA was added to a final concentration of $30 \mu \mathrm{M}$, and incubated for an additional $15 \mathrm{~min}$ at $37^{\circ} \mathrm{C}$. The reaction 
was stopped by centrifugation (900 rpm) for $5 \mathrm{~min}$ at $4^{\circ} \mathrm{C}$. To prepare the $\mathrm{H}$-iridoid products, $1 \mathrm{mM}$ of each iridoid glucoside was pre-incubated with the same volume of $0.5 \mathrm{mM}$ of $\beta$-glucosidase (iridoid: enzyme $=1.0: 0.5 \mathrm{v} / \mathrm{v}$ ), and diluted by adding distilled water to the specified concentrations. Under this condition, almost all iridoid glycosides were easily converted by $\beta$-glucosidase into their hydrolyzed products (12). The concentration of $\mathrm{TXB}_{2}$ in the supernatant was measured by using the ELISA method.

\section{COX-2 Assay using RAW 264.7 Cells}

A murine macrophage cell line, RAW 264.7 cells (ATCC), was maintained at $37^{\circ} \mathrm{C}$ in DMEM medium (Gibco BRL) containing 10\% fetal calf serum, $2 \mathrm{mM}$ L-glutamine, penicillin $(100 \mathrm{U} / \mathrm{ml})$ and streptomycin $(100 \mu \mathrm{g} / \mathrm{ml})$. Cells were cultured at a density of approximately $2 \times 10^{5}$ cells $/ \mathrm{ml}$, then harvested and re-suspended in a fresh medium at a concentration of $1 \times 10^{6}$ cells $/ \mathrm{ml}$. Immediately after adding hydrolyzed-iridoid samples (H-iridoids), the cells were incubated for $30 \mathrm{~min}$ at $37^{\circ} \mathrm{C}$. Then the cells were stimulated with LPS (final concentration of $1 \mu \mathrm{g} / \mathrm{ml}$ ) and incubated for an additional $6 \mathrm{~h}$. Thereafter, similar assaying procedures were followed as done in COX-1 assay using HEL cells. However, instead of adding $\mathrm{TXB}_{2}, \mathrm{PGE}_{2}$ was added to the testing solutions, and the $\mathrm{PGE}_{2}$ concentration in the supernatant was measured using the ELISA method.

\section{Assay of TNF- $\alpha$ Formation}

RAW 264.7 cells $\left(2.5 \times 10^{5}\right.$ cells/well $)$ were treated with LPS/IFN- $\gamma$ in the presence or the absence of the testing iridoid samples for $4 \mathrm{~h}$, and the assay was performed as described previously (10).

\section{Assay of NO Production}

Accumulated concentrations of $\mathrm{NO}_{2}^{-}$in the medium were measured as an indicator of NO production. The assay procedure was the same as described previously (13). Briefly, RAW 264.7 cells were plated each at a concentration of $1.5 \times 10^{6}$ cells $/ \mathrm{ml}$ and stimulated with LPS in the presence or the absence of the testing iridoid samples for $24 \mathrm{~h}$. Each separated supernatant was mixed with an equal volume of Griess reagent ( $1 \%$ sulfanilamide, $0.1 \%$ naphthylethylenediamine dihydrochloride and $2 \%$ phosphoric acid) and incubated at room temperature in the dark for $10 \mathrm{~min}$. The production of $\mathrm{NaNO}_{2}$ was measured at $550 \mathrm{~nm}$.

\section{Statistics}

Data expressed as the mean \pm standard deviation were obtained from three or four separate experiments.
Table 1. Inhibition of $\mathrm{TXB}_{2}$ (thromboxane $\mathrm{B}_{2}$ ) formation in intact HEL cells by hydrolyzed-iridoids (H-iridoids)

\begin{tabular}{lrlll}
\hline Test sample & \multicolumn{1}{c}{$1 \mu \mathrm{M}$} & $10 \mu \mathrm{M}$ & $50 \mu \mathrm{M}$ & $100 \mu \mathrm{M}$ \\
\hline H-aucubin & $101.3 \pm 3.0$ & $97.6 \pm 6.4$ & $84.0 \pm 4.5$ & $68.6 \pm 3.0^{\dagger}$ \\
H-catalpol & $101.3 \pm 3.0$ & $91.3 \pm 5.0$ & $94.0 \pm 9.5$ & $92.0 \pm 4.0$ \\
H-loganin & $91.0 \pm 2.6$ & $57.6 \pm 5.5^{*}$ & $55.0 \pm 5.2^{*}$ & $46.6 \pm 6.4^{*}$ \\
H-gentiopicroside & $101.3 \pm 3.0$ & $90.0 \pm 3.4$ & $92.0 \pm 8.5$ & $88.6 \pm 3.0$ \\
H-swertiamarin & $98.0 \pm 6.0$ & $88.6 \pm 5.1$ & $89.0 \pm 7.0$ & $91.6 \pm 8.1$ \\
H-geniposide & $91.6 \pm 2.5$ & $67.3 \pm 3.0^{*}$ & $54.6 \pm 9.5^{*}$ & $51.6 \pm 3.2^{*}$ \\
H-geniposidic acid & $91.6 \pm 6.5$ & $92.0 \pm 8.5$ & $92.3 \pm 5.6$ & $89.0 \pm 3.6$ \\
genipin & $88.3 \pm 5.3$ & $86.6 \pm 4.2$ & $84.0 \pm 7.0$ & $88.3 \pm 6.1$ \\
\hline
\end{tabular}

Values are presented as mean $\pm \mathrm{SD}$ of the percentage of $\mathrm{TXB}_{2}$ formation of cultures treated with vehicle (DMSO) only.

*Statistically significant difference: $P<0.05$.

Statistical analysis of the data was performed by oneway analysis of variances followed by Dunnett's test. Values of $P<0.05$ were considered statistically significant. Each $\mathrm{IC}_{50}$ value was calculated by non-linear regression analysis (14).

\section{Results}

\section{Effects on Cell Viability}

Cell viability tests were performed throughout all experiments by using the MTT assay. In all iridoid test samples including $\mathrm{H}$-iridoids at a concentration up to $100 \mu \mathrm{M}$, no significant cytotoxicity was observed (data not shown).

\section{Inhibitory Activities on COX-1 Enzyme}

To examine potential inhibitory activities of iridoid samples on COX-1, the amounts of $\mathrm{TXB}_{2}$ reduction were measured in intact HEL cell culture (Table 1). The aspirin, a typical non-steroidal, anti-inflammatory drug, and the piroxicam, a specific COX-1 inhibitor, were employed as positive control drugs. Both control drugs showed inhibitory activities on COX-1 assay in dosedependant manner with $\mathrm{IC}_{50}$ of 7.23 and $0.31 \mu \mathrm{M}$, respectively (Table 2). None of iridoid glycosides without pre-treating $\beta$-glucosidase exhibited any significant inhibitory activities on COX-1 assay. Of those iridoid glycosides which were pre-treated with $\beta$-glucosidase, both $\mathrm{H}$-geniposide and $\mathrm{H}$-loganin produced high inhibitory activities on COX-1 assay, revealing $\mathrm{IC}_{50}$ values of 5.37 and $3.55 \mu \mathrm{M}$, respectively. The $\mathrm{H}$-aucubin showed an $\mathrm{IC}_{50}$ value of $68.9 \mu \mathrm{M}$, indicating relatively less potency than H-geniposide and H-loganin. Other H-iridoid samples and genipin (aglycone) exhibited no significant inhibitory activities on COX-1 assay. 
Table 2. $\mathrm{IC}_{50}$ values of positive controls and hydrolyzed-iridoids (H-iridoids) for the inhibition of COX-1/-2 enzymes activities, the formation of $\mathrm{TNF} \alpha$ and the production of $\mathrm{NO}$

\begin{tabular}{lllll}
\hline & COX-1 $(\mu \mathrm{M})$ & COX-2 $(\mu \mathrm{M})$ & TNF $\alpha(\mu \mathrm{M})$ & NO $(\mu \mathrm{M})$ \\
\hline Aspirin & 7.23 & 14.2 & - & - \\
Piroxicam & 0.31 & - & - & - \\
Meloxicam & - & 0.16 & - & - \\
Rolipram & - & - & 0.11 & \\
L-NAME & - & - & - & 14.4 \\
H-Aucubin & 68.9 & 8.83 & 11.2 & 14.1 \\
H-Catalpol & ND & ND & 33.3 & ND \\
H-Loganin & 3.55 & 131.0 & 154.6 & ND \\
H-Geniposide & 5.37 & 32.4 & 58.2 & ND \\
\hline
\end{tabular}

$\mathrm{ND}$, not determined.

Table 3. Inhibition of $\mathrm{PGE}_{2}$ (prostaglandin $\mathrm{E}_{2}$ ) formation in LPSstimulated RAW264.7 cells by hydrolyzed-iridoids (H-iridoids)

\begin{tabular}{lllll}
\hline Test sample & $1 \mu \mathrm{M}$ & $10 \mu \mathrm{M}$ & $50 \mu \mathrm{M}$ & $100 \mu \mathrm{M}$ \\
\hline H-aucubin & $92.3 \pm 8.5$ & $64.6 \pm 6.4^{*}$ & $41.3 \pm 8.0^{*}$ & $37.3 \pm 4.0^{*}$ \\
H-catalpol & $88.0 \pm 4.0$ & $87.0 \pm 7.2$ & $76.0 \pm 8.8$ & $75.3 \pm 4.9^{*}$ \\
H-loganin & $93.3 \pm 6.1$ & $88.0 \pm 8.5$ & $75.6 \pm 9.2^{*}$ & $55.3 \pm 6.5^{*}$ \\
H-gentiopicroside & $93.0 \pm 6.5$ & $95.6 \pm 6.4$ & $84.6 \pm 4.7$ & $86.0 \pm 7.9$ \\
H-swertiamarin & $96.3 \pm 9.2$ & $89.0 \pm 5.2^{*}$ & $84.6 \pm 14.5$ & $86.0 \pm 7.9$ \\
H-geniposide & $95.3 \pm 5.0$ & $89.3 \pm 6.6$ & $71.3 \pm 9.0^{*}$ & $64.0 \pm 7.2^{*}$ \\
H-geniposidic acid & $94.3 \pm 6.6$ & $93.6 \pm 2.3$ & $86.0 \pm 7.9$ & $78.0 \pm 8.7$ \\
genipin & $92.3 \pm 6.8$ & $90.0 \pm 6.2$ & $84.6 \pm 7.3$ & $91.3 \pm 6.7$ \\
\hline
\end{tabular}

Values are presented as mean $\pm \mathrm{SD}$ of the percentage of $\mathrm{PGE}_{2}$ formation of cultures treated with vehicle (DMSO) only.

*Statistically significant difference: $P<0.05$.

\section{Inhibitory Activities on COX-2 Enzyme}

Experiments using LPS-stimulated RAW 264.7 cells were conducted to examine inhibitory activities on COX-2 as described in Methods; the formation of the $\mathrm{PGE}_{2}$ was measured and data were shown in Table 3. Both aspirin and meloxicam were used as positive control drugs for COX-2 inhibitors. Both control drugs exhibited inhibitory activities in dose-dependant manner with $\mathrm{IC}_{50}$ of 14.2 and $0.16 \mu \mathrm{M}$, respectively (Table 2). Contrary to the data obtained from COX-1 assay, we observed that $\mathrm{H}$-aucubin exhibited a higher inhibition on COX-2 assay $\left(\mathrm{IC}_{50}\right.$ value of $\left.8.83 \mu \mathrm{M}\right)$; whereas $\mathrm{H}$-geniposide and $\mathrm{H}$-loganin, produced much less inhibition with $\mathrm{IC}_{50}$ values of 32.4 and $131.0 \mu \mathrm{M}$, respectively.

\section{Suppression of TNF- $\alpha$ Formation}

The assay was performed by using an ELISA method in RAW 264.7 cells that were stimulated with LPS/IFN- $\gamma$ as described in Methods. The rolipram, a positive control
Table 4. Inhibition of $\mathrm{TNF} \alpha$ (tumor necrosis factor) production in LPS-stimulated RAW264.7 cells by hydrolyzed-iridoids (H-iridoids)

\begin{tabular}{lclll}
\hline Test sample & $1 \mu \mathrm{M}$ & $10 \mu \mathrm{M}$ & $50 \mu \mathrm{M}$ & $100 \mu \mathrm{M}$ \\
\hline H-aucubin & $85.6 \pm 11.0$ & $63.6 \pm 5.5^{*}$ & $44.6 \pm 10.5^{*}$ & $24.0 \pm 7.9^{*}$ \\
H-catalpol & $95.6 \pm 4.0$ & $92.3 \pm 8.0$ & $69.3 \pm 6.5^{*}$ & $67.3 \pm 8.9^{*}$ \\
H-loganin & $96.6 \pm 4.1$ & $84.6 \pm 5.1^{*}$ & $71.0 \pm 6.5^{*}$ & $45.3 \pm 3.5^{*}$ \\
H-gentiopicroside & $89.6 \pm 4.0$ & $89.0 \pm 6.0$ & $82.6 \pm 6.6$ & $86.0 \pm 6.5$ \\
H-swertiamarin & $89.6 \pm 4.0$ & $93.6 \pm 2.0$ & $86.3 \pm 4.7$ & $89.3 \pm 4.0$ \\
H-geniposide & $93.3 \pm 4.1$ & $88.0 \pm 8.5$ & $71.0 \pm 3.6^{*}$ & $55.6 \pm 4.0^{*}$ \\
H-geniposidic acid & $100.0 \pm 2.0$ & $94.6 \pm 12.5$ & $84.0 \pm 15.5$ & $82.3 \pm 7.3^{*}$ \\
genipin & $102.3 \pm 8.8$ & $97.6 \pm 7.3$ & $94.0 \pm 9.3$ & $96.6 \pm 8.1$ \\
\hline
\end{tabular}

Values are presented as mean $\pm \mathrm{SD}$ of the percentage of $\mathrm{TNF} \alpha$ production of cultures treated with vehicle (DMSO) only.

*Statistically significant difference: $P<0.05$.

Table 5. Inhibition of NO (nitric oxide) production in LPS-stimulated RAW264.7 cells by hydrolyzed-iridoids (H-iridoids)

\begin{tabular}{lcccc}
\hline Test sample & $1 \mu \mathrm{M}$ & $10 \mu \mathrm{M}$ & \multicolumn{1}{c}{$50 \mu \mathrm{M}$} & $100 \mu \mathrm{M}$ \\
\hline H-aucubin & $96.3 \pm 7.4$ & $71.3 \pm 9.0^{*}$ & $49.0 \pm 9.8^{*}$ & $40.0 \pm 3.6^{*}$ \\
H-catalpol & $96.0 \pm 4.0$ & $87.0 \pm 7.2$ & $86.0 \pm 8.8$ & $85.3 \pm 5.9$ \\
H-loganin & $93.3 \pm 6.1$ & $98.0 \pm 8.5$ & $95.6 \pm 9.2$ & $105.3 \pm 6.5$ \\
H-gentiopicroside & $103.3 \pm 6.5$ & $95.6 \pm 6.4$ & $94.6 \pm 4.7$ & $96.0 \pm 7.9$ \\
H-swertiamarin & $96.3 \pm 9.2$ & $89.0 \pm 5.1$ & $84.6 \pm 14.5$ & $84.2 \pm 7.9$ \\
H-geniposide & $95.3 \pm 5.0$ & $89.3 \pm 6.6$ & $101.3 \pm 9.0$ & $104.6 \pm 7.2$ \\
H-geniposidic acid & $94.3 \pm 6.6$ & $93.6 \pm 2.3$ & $86.0 \pm 7.9$ & $98.3 \pm 8.7$ \\
genipin & $104.6 \pm 8.8$ & $105.2 \pm 10.0$ & $111.3 \pm 11.0$ & $106.3 \pm 13.4$ \\
\hline
\end{tabular}

Values are presented as mean $\pm \mathrm{SD}$ of the percentage of NO production of cultures treated with vehicle (DMSO) only.

*Statistically significant difference: $P<0.05$.

drug, suppressed the TNF- $\alpha$ formation by $86 \%$ even at a concentration of $1 \mu \mathrm{g} / \mathrm{ml}$. Unlike those results obtained from COX-1/-2 experiments, suppression of TNF- $\alpha$ formation was apparently more sensitive to a variety of testing iridoids as noted as four H-iridoid samples, $\mathrm{H}$-aucubin, H-catalpol, H-geniposide and H-loganin, showed suppressive activities with $\mathrm{IC}_{50}$ values of 11.2 , 33.3, 58.2 and $154.6 \mu \mathrm{M}$, respectively (Tables 2 and 4). Other $\mathrm{H}$-iridoids and genipin did not have much influence on the suppression of $\mathrm{TNF}-\alpha$ formation.

\section{Suppression of NO Production}

To examine suppressive activities of $\mathrm{H}$-iridoids on $\mathrm{NO}$ production, the LPS-stimulated RAW 264.7 cells were used (Table 5). The L-NAME, a well-known inhibitor, was used as a positive control. Treatments of L-NAME suppressed significantly the NO production in dosedependant manners with an $\mathrm{IC}_{50}$ value of $14.4 \mu \mathrm{M}$ (Table 2). Of H-iridoid samples tested so far, only $\mathrm{H}$-aucubin exhibited a significant suppression with an 
$\mathrm{IC}_{50}$ value of $14.1 \mu \mathrm{M}$, indicating almost the same potency as that of the L-NAME treatment. In the view that the chronic suppression of NO may lead to heart disease, it is worth investigating the effect of $\mathrm{H}$-aucubin on the cardiovascular system.

\section{Discussion}

Iridoids, naturally occurring substances, are found in many medicinal herbs including traditional Chinese herbs. They exist mostly as glycosides and some are found in genin forms without glycoside moiety in their structure. Those medicinal plants containing iridoids show a variety of biological activity as aforementioned. Of pharmaceutical products as well as dietary supplements containing such medicinal plant materials, agents (e.g. devil's claw products made of Harpagophytum) for treating inflammatory ailments including rheumatic inflammation have been marketed and used for long time. To verify the molecular mechanism of antiinflammatory activities of iridoid analogs, we carried out the present study.

Based on the results obtained so far, we confirmed our previous findings in which iridoid glycoside itself is in inactive forms, and it should be converted to its active form by enzymatic hydrolysis of glycosidic bond, leading to its $\mathrm{H}$-iridoid products $(1,10)$. Although no definite structure of $\mathrm{H}$-iridoid products has been determined yet, it is presumed to produce a cleavage of monoterpene rings, resulting in the active form of the drug $(2,12)$. To support such a postulation, we challenged the genipin (aglycone) without $\beta$-glucosidase treatment into all assay models in vitro; the animal cells (HEL and RAW 264.7) do not have $\beta$-glucosidase and aglycone form of genipin is more easily transported into the cell membrane than iridoid glycosides are. As anticipated, no inhibitory activities were noted in all three assay models. These results imply a similar bio-process occurs in whole animal systems for pharmacological actions of iridoid-containing herbs. In this connection, it is also mentioned that some iridoids such as geniposide and gardenoside are converted to nitrogen-containing metabolites (genipinine and gardenine) by intestinal bacterial flora (15). However, it is uncertain what kinds of biological action can occur with these genins.

Taking into consideration the structural differences versus potency of anti-inflammatory activities, only a minute structural difference renders a marked different potency to each iridoid. H-geniposide and $\mathrm{H}$-loganin exhibited high inhibitory potencies on COX-1; whereas $\mathrm{H}$-aucubin showed very low inhibition on COX-1. However, $\mathrm{H}$-aucubin produced a moderate inhibition on COX-2. In addition, H-aucubin only exhibited suppressive activities on both NO production and TNF- $\alpha$ formation. But $\mathrm{H}$-catalpol, which is a very similar structure with $\mathrm{H}$-aucubin, revealed no significant inhibition on COX-1/2 and NO production. In this regard, further studies are needed with respect to the structural determination of $\mathrm{H}$-iridoid products. A single medicinal herb usually contains a mixture of different analogues of iridoids and different contents of iridoids, depending on the plant's parts. Such differences may render different pharmacological activities to each medicinal herb containing iridoids. Nonetheless, the present study provides important information for selecting more effective antiinflammatory herbs among the many medicinal plants containing iridoids.

\section{Acknowledgement}

This work was supported in part by the Seoul National University Grants (2006).

\section{References}

1. Chang I-M. Liver-protective activities of aucubin derived from traditional original medicine. Res Commun Mol Pathol Pharmacol 1998;102:189-204.

2. Konno K, Hirayama C, Yasui H, Nakamura M. Enzymatic activation of oleuropein: A protein crosslinker used as a chemical defense in the privet tree. Proc Natl Acad Sci 1999;96:9159-64.

3. Chang I-M, Ryu JC, Park YC, Yun HS, Yang KH. Protective activities of AU against carbon tetrachloride-induced liver damage in mice. Drug Chem Toxicol 1983;6:443-53.

4. Miyagoshi M, Amagaya S, Ogihara Y. Choleretic actions of iridoid compounds. Pharmacobiodyn 1988;11:186-9.

5. Davini E, Iavarone C, Trogolo C, Aureli P, Pasolini B. The quantitative isolation and antimicrobial activity of the aglycone of aucubin. Phytochemistry 1986;25:2420-2.

6. Konoshima T, Takasaki M, Tokuda H, Nishino H. Cancer chemopreventive activity of an iridoid glycoside, 8-acetylharpagide, from Ajuga decumbens. Cancer Lett 2000;157:87-92.

7. Chang I-M, Yamaura Y. Aucubin: a new antidote for poisonous Amanita mushrooms. Phytother Res 1993;7:53-6.

8. Chang I-M. Antiviral activity of aucubin against Hepatitis B virus replication. Phytother Res 1997;11:189-92.

9. Recio MC, Giner RM, Manez S, Rios JL. Structural considerations on the iridoids as anti-inflammatory agents. Planta Med 1994;60:232-4.

10. Park KS, Chang I-M. Anti-inflammatory activity of aucubin by inhibition of tumor necrosis factor- $\alpha$ production in RAW264.7 cells. Planta Med 2004;70:778-9.

11. Berg J, Christoph T, Widerna M, Bodenteich A. Isoenzyme-specific cyclooxygenase inhibitors: a whole cell assay system using the human erythroleukemic cell line HEL and the human monocytic cell line Mac 6. J Pharmacol Toxicol Methods 1997;37:179-86.

12. Bartholomaeus A, Ahokas J. Inhibition of P-450 by aucubin: is the biological activity of aucubin due to its glutaraldehyde-like aglycone? Toxicol Lett 1995;80:75-83.

13. Gupta V, Gupta A, Saggu S, Divekar HM, Grover SK, Kumar R. Anti-stress and adaptogenic activity of L-arginine supplementation. Evid Based Complement Alternat Med 2005;2:93-7.

14. Bowen WP, Jerman JC. Nonlinear-regression using spreadsheets. TIPS 1995;16:413-7.

15. Kawata Y, Hattori M, Akao T, Kobashi K, Namba T. Formation of nitrogen-containing metabolites from geniposide and gardenoside by human intestinal bacteria. Planta Med 1991;57:536-42.

Received November 19, 2006; accepted July 27, 2007 


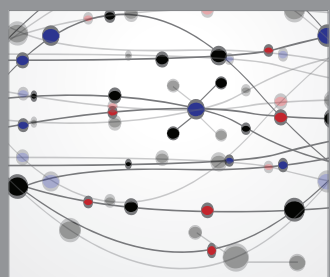

The Scientific World Journal
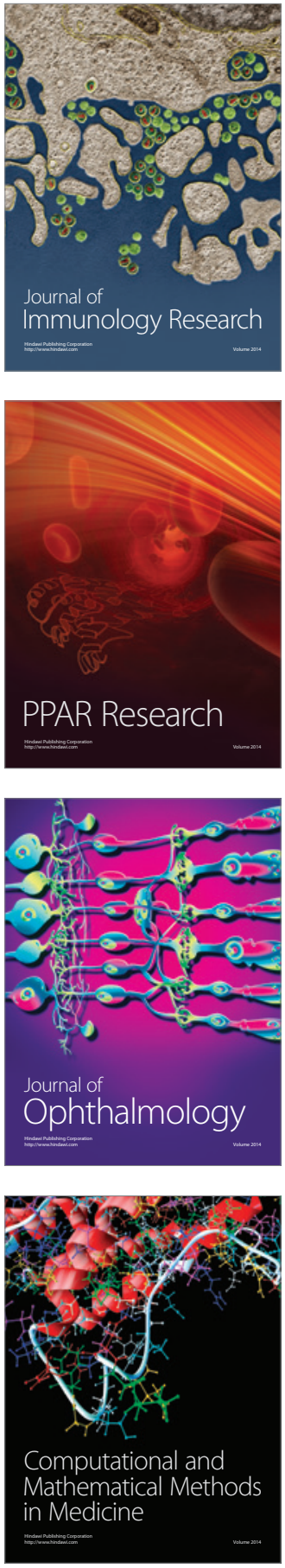

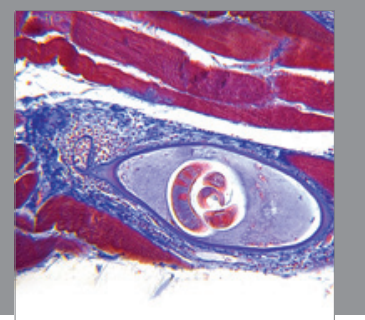

Gastroenterology

Research and Practice
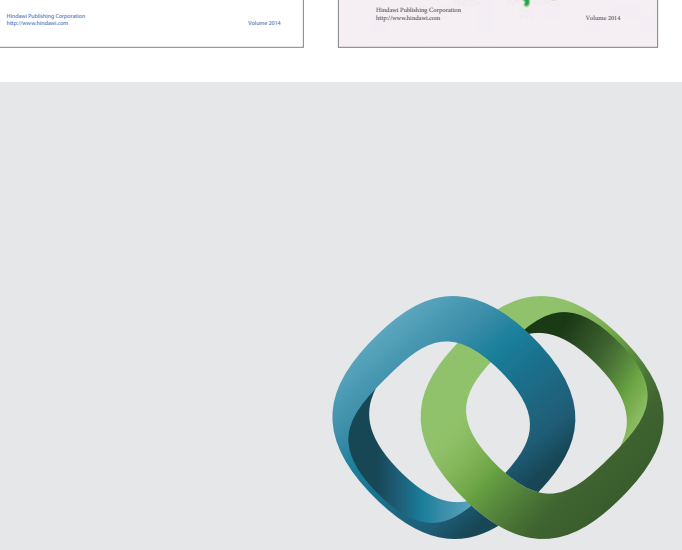

\section{Hindawi}

Submit your manuscripts at

http://www.hindawi.com
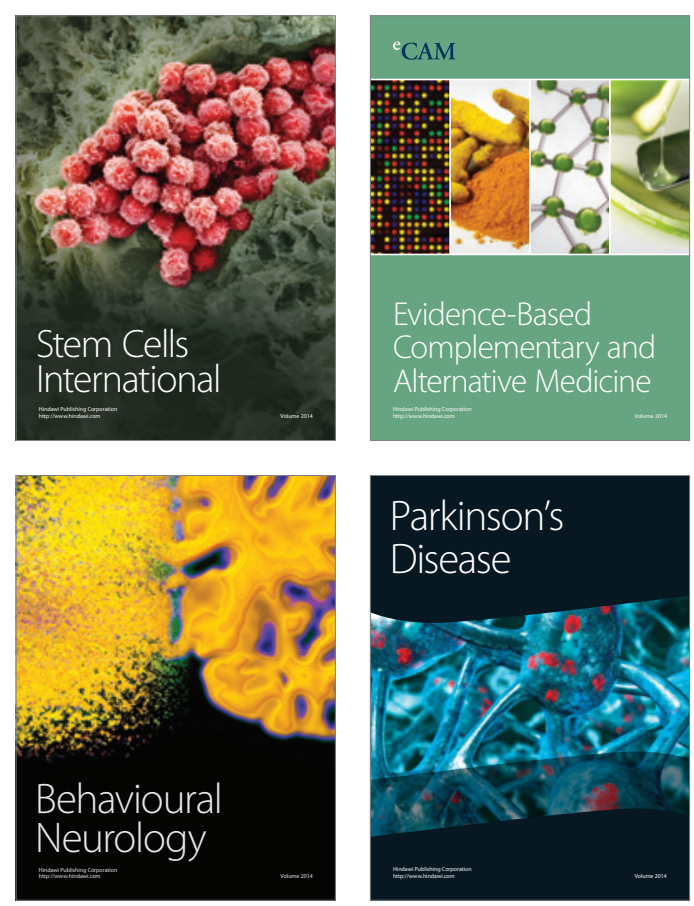

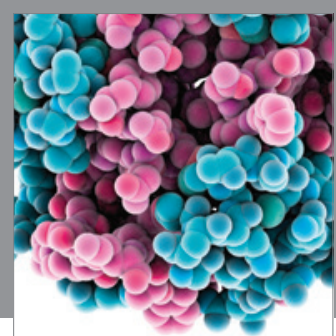

Journal of
Diabetes Research

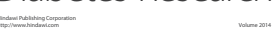

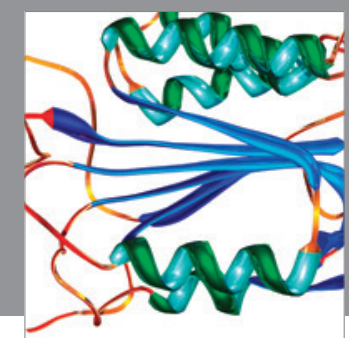

Disease Markers
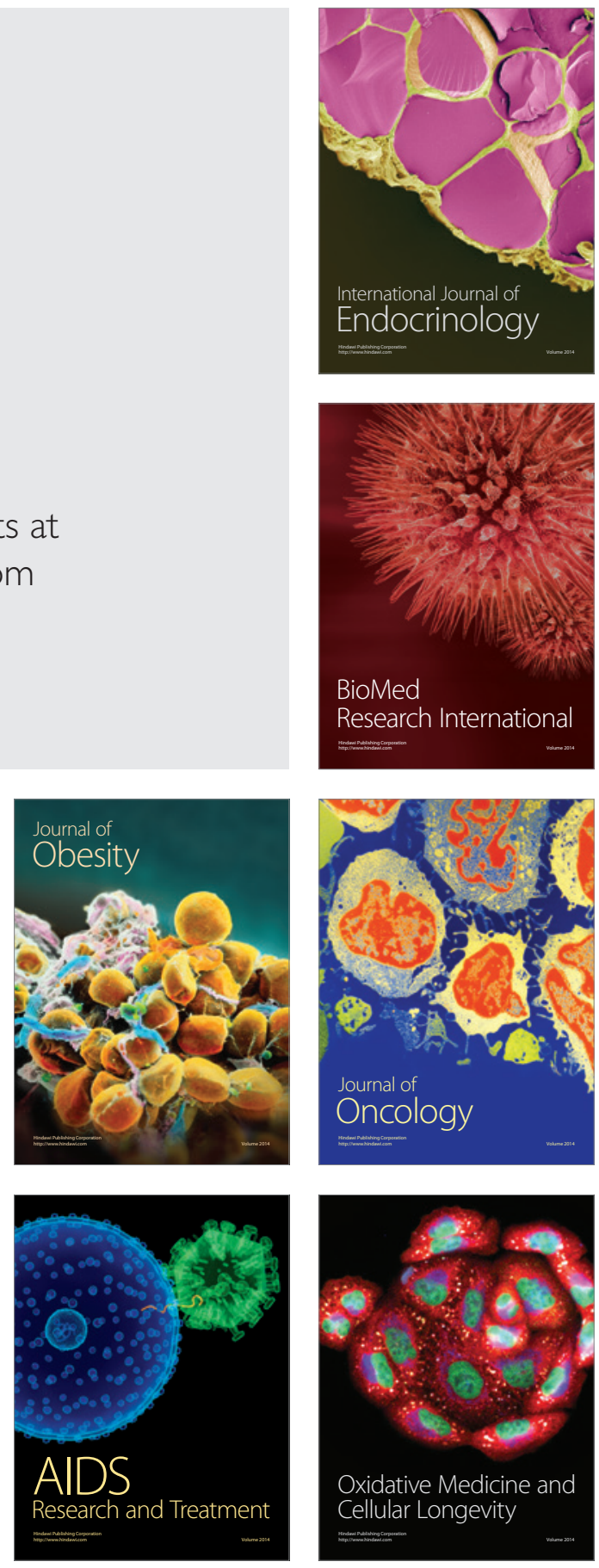